\title{
A descriptive study of the effect of a disciplinary proceeding decision on medical practitioners' practice behaviour in the context of providing a hydrocortisone and lignocaine injection
}

Chiang Yin Wong ${ }^{1}$, MMed, FAMS, Subramaniam Surajkumar ${ }^{2}$, MBBS, MMed, Yik Voon Lee ${ }^{1}$, MBBS, GDMH, Tze Lee $\underline{T^{2}}{ }^{2}$ MBChBEd, FCFPS

\begin{abstract}
INTRODUCTION We conducted a descriptive study to evaluate any changes in practice behaviour regarding the provision of hydrocortisone and lignocaine (H\&L) injections among doctors and how an H\&L injection is priced following a disciplinary proceeding decision. A doctor had been fined SGD 100,000 for failing to obtain informed consent before an H\&L injection. METHODS We performed a survey shortly after the disciplinary decision to ascertain: (a) the category of the respondent; (b) whether the respondent provided H\&L injections and how much he charged before the decision; and (c) after the decision. All members of the Singapore Medical Association and College of Family Physicians Singapore are doctors and were invited to participate.

RESULTS 1,927 doctors responded to the survey. Prior to the decision, 804 doctors did not perform H\&L injections; this increased by $20.4 \%$ to 968 after the decision. The number of doctors who gave H\&L injections decreased by 164 (14.6\%), from the previous 1,123. Pre-decision, doctors who determined their own price for H\&L injections charged a median pricing $\leq$ SGD 100. Post-decision, the median charge rose to > SGD 100 to SGD 200. At higher price bands, the number of doctors who charged > SGD 1,000 increased eight-fold, from eight to 65 .

CONCLUSION The study demonstrated how a disciplinary decision can affect practice behaviour, and specifically how doctors may choose to not offer a service, an example of defensive medicine through avoidance behaviour. It also showed how prices for a service can rise following such a decision, which demonstrates the concept of negative general deterrence in sentencing.
\end{abstract}

Keywords: defensive medicine, deterrence, informed consent, practice behaviour, Singapore

\section{INTRODUCTION}

A change in a doctor's practice behaviour can be attributed to a variety of factors. The main factors include advances in technology and the availability of new diagnostic and therapeutic options, funding and payment models; new models of care, such as team-based care, community and home care; and evolving patient expectations. Many of these factors have been studied extensively. A less-examined factor, compared to the aforesaid, is the perceived change in ethical standards or the medico-legal environment.

We conducted a descriptive study to evaluate changes in behaviour, if any, among doctors as a result of a disciplinary proceeding decision. The decision involved the issue of informed consent for the provision of a hydrocortisone and lignocaine $(H \& L)$ injection. Specifically, we aimed to know if this change in behaviour would lead to: (a) an increase in the practice of defensive medicine through avoidance behaviour; and/or (b) an increase in the price of an $\mathrm{H} \& \mathrm{~L}$ injection for the patient.

The Singapore Medical Council (SMC) is a self-regulatory statutory body that regulates the ethical behaviour and professional conduct of registered medical practitioners (i.e. doctors) in Singapore. The provision for SMC to exist is empowered by legislation, specifically the Medical Registration Act (MRA). When a formal complaint is made to the SMC, a Complaints Committee (CC) is set up. Investigations are carried out and the defendant doctor is asked to give a written report to the CC. The CC then deliberates on the information and is empowered under Section 49 of the MRA to make certain decisions, including determining if a formal inquiry is necessary. If a formal inquiry is deemed necessary, the SMC proceeds to set up a disciplinary tribunal (DT).

The SMC then appoints members to the DT, which sits to hear and judge complaints against doctors, as provided for under Section 50(1) of the MRA. The DT usually consists of two senior doctors and one legally trained person, usually a legal service officer or a senior legal counsel. The SMC also appoints a lawyer to prosecute the defendant doctor on behalf of the complainant. In a DT proceeding, three parties are present: the defendant doctor, the SMC lawyer and the three members of the DT, who 'judge' the case and pronounce a decision on whether the doctor is guilty of professional misconduct. The defending doctor is entitled to have his legal counsel at DT hearings, as provided for under Section 51(3) of the MRA. Defendant doctors and witnesses can be cross-examined at DT hearings, similar to what happens in a typical adversarial legal process. An appeal can be made to the Court of Three Judges (C3J) - consisting of three High Court Judges - if the defendant SMC (under the instruction of the SMC 
Review Committee) or the complainant is dissatisfied with the decision of the DT (Section 55 of the MRA).

Section 53(1) of the MRA spells out the possible findings of a DT that may lead to a DT imposing sanctions on the defendant doctor under Section 53(2). These are: (a) to have been convicted in Singapore or elsewhere of any offence involving fraud or dishonesty; (b) to have been convicted in Singapore or elsewhere of any offence implying a defect in character which makes him unfit for his profession; (c) to have been guilty of such improper act or conduct which, in the opinion of the DT, brings disrepute to his profession; (d) to have been guilty of professional misconduct; or (e) to have failed to provide professional services of the quality which is reasonable to expect of him. As of 31 December 2017, there are 13,944 doctors licensed by SMC to practise medicine in Singapore. ${ }^{(1)}$

An H\&L injection usually involves a mixture of a local anaesthetic (e.g. lignocaine) and a steroid (e.g. hydrocortisone or triamcinolone) that is given to relieve pain and treat the inflammation involved in many common musculoskeletal conditions, such as plantar fasciitis, tendinitis conditions (e.g. tennis elbow, trigger finger and De Quervain's tenosynovitis), shoulder conditions (e.g. frozen shoulder and rotator cuff injuries) and a variety of arthritic conditions including osteoarthritis, rheumatoid arthritis and reactive arthritis.

The case concerned an orthopaedic surgeon in private practice, Dr LLA, who performed an H\&L injection on a patient on 27 October 2014. The patient subsequently developed some complications. About 14 months later, the patient lodged a complaint with the SMC, stating that Dr LLA did not explain the possible complications and risks of the H\&L injection. Specifically, the charge against Dr LLA included a long list of potential complications that could arise from an $\mathrm{H} \& \mathrm{~L}$ injection.

Dr LLA pleaded guilty. The counsel for the SMC submitted that the "appropriate, proportionate and effective sentence in this case" should be a suspension of five months. ${ }^{(2)}$ Had Dr LLA not pleaded guilty early, the counsel for the SMC would have asked for a longer suspension of six to eight months. The counsel for Dr LLA asked for the maximum fine of SGD 100,000 to "serve the aim of a proportionate general deterrence" or a suspension of three months instead if the DT "was of the view that a suspension was necessary as a type of punishment for general deterrence". (3) Dr LLA was found guilty of professional misconduct and fined the maximum of SGD 100,000 and censured. He was also asked to pay the costs and expenses of and incidental to the disciplinary proceedings, including the costs of the solicitors to the SMC, and to give a written undertaking to the SMC that he would not engage in the conduct complained of or any similar conduct.

In the DT's grounds of decision (GD) for this case, it was stated that:

- $\quad$ "there was no evidence that the patient would have taken a different course of action had such information been conveyed to her"(4)

- $\quad$ "It was an honest omission on Dr LLA's part"(5)

- $\quad$ "In our (i.e. the DT's) view, the patient retained much of her autonomy ${ }^{\prime \prime 6)}$
- $\quad$ "the H\&L injection administered... was... an appropriate and reasonable treatment of the patient"(7)

- $\quad$ "Hence, while the tribunal recognised that the patient suffered some side effects and complications resulting from the H\&L injection... there is nothing to suggest that the complications experienced by the complainant were in any way permanent or debilitating"(8)

This event was extensively reported in the local media and caused significant disquiet in the local medical profession when the GD was made public on 21 January 2019. A petition that garnered 6,401 signatures stated: "This is a landmark decision by the SMC. The practice of medicine in Singapore will henceforth be completely legalistic, if all complications and side effects must be told to each and every patient. There is no doubt in our minds that this will drive up healthcare costs significantly, slow down the delivery of care, and increase waiting times, especially for patients treated in the restructured institutions. This will be to the detriment of all Singaporeans. It is time for the Minister of Health to step in and clarify if this is the direction that healthcare in Singapore should take". ${ }^{(9)}$

On 30 January 2019, in a letter to all registered medical practitioners, the SMC clarified that doctors were not expected to inform patients of all possible complications. The letter stated: "It should be emphasised that Dr Lim was charged for wholly failing to inform the patient of any possible complications and not for failing to inform the patient of all possible complications that could arise from the H\&L injection" ${ }^{\prime(10)}$

The Ministry of Health $(\mathrm{MOH})$ on 20 February 2019 then requested SMC to appeal to the High Court to review the decision of the SMC DT to impose the fine of SGD 100,000. In a press release by $\mathrm{MOH}$ accompanying this move, it was stated: "Whilst both Dr Lim and the SMC may have accepted the sentence, the decision in this case carries with it much wider professional practice implications and also has an impact on future cases. $\mathrm{MOH}$ is of the view that this decision should be reviewed. We are concerned that this case should not be viewed as or lead to the practice of defensive medicine which would have an adverse impact on patient and clinical safety. There have also been questions raised about the liability imposed in this case. In light of the above circumstances, $\mathrm{MOH}$ has requested for the SMC to apply to court for the decision to be reviewed, and for the appropriate revisions to be made. It will be good to have the matter thoroughly reviewed in court. SMC has agreed, and has filed the application in court to seek permission from the court to have this decision reviewed despite the time for appeal having passed". ${ }^{(11)}$

\section{METHODS}

The College of Family Physicians (CFPS), with the collaboration of the Singapore Medical Association (SMA), conducted a survey to examine whether the DT's decision had affected the practice of medicine in Singapore. CFPS is an institution that enshrines and promotes the values and ideals of family medicine, and represents general practitioners (GPs) and family physicians (FPs) in Singapore. It has 2,401 members and is committed 
to the advocacy and training of FPs. The SMA is the national medical association in Singapore. As of end-2018, it has 5,990 members, ${ }^{(12)}$ all of whom are registered medical practitioners, and membership is voluntary.

The survey was conducted using the Web survey application SurveyMonkey. An invitation to participate in the survey was sent by email from the two professional bodies, CFPS and SMA, to all its members on 13 February 2019. The survey consisted of three questions, which are stated in Box 1.

The three questions were dropdown single-choice questions. Each respondent was allowed to select one response out of the predetermined possible responses to each question (Tables I \& II). The survey was deliberately kept simple and short so as to facilitate a higher response rate among doctor-respondents who may not have had the time to respond to a long questionnaire.

An email reminder was sent on 18 February 2019. As there were a significant number of doctors who were members of both CFPS and SMA, there was a note in the email for those who were members of both professional bodies to only respond once to minimise the chance of these members responding more than once. Furthermore, the link to the survey was such that a doctor could respond to the survey only once from the same IP (Internet Protocol) address.

As this study did not involve patient or patient data, institutional review board approval was not sought.

\section{RESULTS}

There were a total of 1,927 complete responses. The responses to Question 1 (classification and number of respondents) are shown in Table I.

In Questions 2 and 3, doctors were asked whether they gave $\mathrm{H} \& \mathrm{~L}$ injections and what their charges were if they did. Questions were further subdivided to find out the usual practice both before the DT's decision and after the DT's decision. The total responses to Questions 2 and 3 are illustrated in Table II.

$\mathrm{H} \& \mathrm{~L}$ injections are commonly performed by GPs, FPs, and hand and orthopaedic surgeons. Around $41.7 \%$ of the respondents did not give H\&L injections in their practice before the DT decision. This increased to $50.2 \%$ after the decision, which translated to a reduction of $164(8.5 \%)$ practitioners, out of a total of 1,927 respondents, who stopped giving $\mathrm{H} \& \mathrm{~L}$ injections following the DT decision. Excluding the 804 respondents who did not give $\mathrm{H} \& \mathrm{~L}$ injections before the DT decision, only 1,123 respondents were still giving the injection. Hence, the decrease of 164 represented a $14.6 \%$ reduction in the number of doctors who provided $\mathrm{H} \& \mathrm{~L}$ injections.

Pre-decision, the number of doctors who gave $\mathrm{H} \& \mathrm{~L}$ injections and could determine their own price for the procedure was 782, and their median pricing was in the S SGD 100 band. Post-decision, the number was 621 . These doctors reported that their median pricing for injections had increased and was now in the > SGD 100 to SGD 200 band. Before the decision, 30.5\% charged $\leq$ SGD 100, but the number decreased to $10.7 \%$ after the decision, representing a reduction of about two-thirds.

Table III shows the breakdown of findings into six categories of doctors. Three of the six categories $(n=1,271)$ consisted of doctors

\section{Box 1. Survey sent to doctors:}

Question 1: Are you a: GP (general practitioner)/FP (family physician) in private practice, a polyclinic doctor, a resident or medical officer in a restructured hospital, a public sector specialist, a private specialist, or a locum?

Question 2: What were your usual charges for an H\&L (hydrocortisone and lignocaine) injection in the past, before the grounds of decision for the Lim Lian Arn case?

Question 3: Since the grounds of decision for the Lim Lian Arn case, what are your charges for an H\&L injection?

Table I. Number and classification of respondents $(n=1,927)$.

\begin{tabular}{|ll|}
\hline Option & No. (\%) \\
\hline GP/FP in private practice & $934(48.5)$ \\
\hline Polyclinic doctor & $175(9.1)$ \\
\hline Resident/medical officer in a restructured hospital & $251(13.0)$ \\
\hline Public sector specialist & $230(11.9)$ \\
\hline Private specialist & $260(13.5)$ \\
\hline Locum & $77(4.0)$ \\
\hline
\end{tabular}

FP: family physician; GP: general practitioner

Table II. How much all respondents charged for H\&L injections before and after the DT's decision ( $n=1,927$ ).

\begin{tabular}{|lll|}
\hline Option & \multicolumn{2}{c|}{ No. (\%) } \\
\cline { 2 - 3 } & $\begin{array}{l}\text { Before } \\
\text { decision }\end{array}$ & $\begin{array}{l}\text { After } \\
\text { decision }\end{array}$ \\
\hline $\begin{array}{l}\text { Not applicable. I do not give H\&L } \\
\text { injections in my practice. }\end{array}$ & $804(41.7)$ & $968(50.2)$ \\
\hline $\begin{array}{l}\text { Not applicable. I give H\&L injections, } \\
\text { but I do not determine the price of the } \\
\text { injection. }\end{array}$ & $341(17.7)$ & $338(17.5)$ \\
\hline Charge (SGD) & & \\
\hline$\leq 100$ & $588(30.5)$ & $206(10.7)$ \\
\hline$>100$ to 200 & $147(7.6)$ & $170(8.8)$ \\
\hline$>200$ to 500 & $34(1.8)$ & $125(6.5)$ \\
\hline$>500$ to 1,000 & $5(0.3)$ & $55(2.9)$ \\
\hline$>1,000$ to 2,000 & $0(0)$ & $22(1.1)$ \\
\hline$>2,000$ to 3,000 & $1(0.1)$ & $6(0.3)$ \\
\hline$>3,000$ & $7(0.4)$ & $37(1.9)$ \\
\hline
\end{tabular}

DT: disciplinary tribunal; H\&L: hydrocortisone and lignocaine

from the private sector, namely GPs/FPs, private specialists and locums, accounting for $66.0 \%$ of all respondents. These three categories of private sector doctors consistently reported a greater increase in the proportion of doctors who stopped giving $\mathrm{H} \& \mathrm{~L}$ injections, compared to the public sector doctors (i.e. polyclinic doctors, public sector specialists and residents/medical officers). The number of private sector doctors who did not give $\mathrm{H} \& \mathrm{~L}$ injections increased from 439 to 592, an increase of $34.9 \%$. The corresponding figure for the public sector was $3.0 \%$, with 376 doctors not giving H\&L injections, or an increase of 11 doctors.

In the private sector, among those who continued to offer $\mathrm{H} \& \mathrm{~L}$ injections, there was an increase in charges for $\mathrm{H} \& \mathrm{~L}$ injections, with fewer doctors charging < SGD 100 and more charging at the higher fee bands. It is also noteworthy that before the decision, 
Table III. Respondents' charges for H\&L injections before and after the DT's decision, according to category of doctor ( $n=1,927)$.

\begin{tabular}{|c|c|c|c|c|c|c|}
\hline \multirow[t]{3}{*}{ Option } & \multicolumn{6}{|c|}{ No. of private sector doctors } \\
\hline & \multicolumn{2}{|c|}{$\begin{array}{l}\text { GP/FP in private } \\
\text { practice }(n=934)\end{array}$} & \multicolumn{2}{|c|}{$\begin{array}{l}\text { Private sector specialist } \\
\qquad(n=260)\end{array}$} & \multicolumn{2}{|c|}{ Locum $(n=77)$} \\
\hline & Before & After & Before & After & Before & After \\
\hline Not applicable. I do not give H\&L injections in my practice. & 236 & 377 & 165 & 168 & 38 & 47 \\
\hline $\begin{array}{l}\text { Not applicable. I give H\&L injections, but I do not } \\
\text { determine the price of the injection. }\end{array}$ & 72 & 73 & 5 & 4 & 26 & 24 \\
\hline \multicolumn{7}{|l|}{ Charge (SGD) } \\
\hline$\leq 100$ & 505 & 175 & 27 & 7 & 9 & 0 \\
\hline$>100$ to 200 & 100 & 138 & 41 & 27 & 2 & 3 \\
\hline$>200$ to 500 & 16 & 94 & 16 & 29 & 2 & 0 \\
\hline$>500$ to 1,000 & 1 & 39 & 3 & 12 & 0 & 3 \\
\hline$>1,000$ to 2,000 & 0 & 14 & 0 & 5 & 0 & 0 \\
\hline$>2,000$ to 3,000 & 0 & 2 & 0 & 3 & 0 & 0 \\
\hline$>3,000$ & 4 & 22 & 3 & 5 & 0 & 0 \\
\hline \multirow[t]{3}{*}{ Option } & \multicolumn{6}{|c|}{ No. of public sector doctors } \\
\hline & \multicolumn{2}{|c|}{$\begin{array}{l}\text { Polyclinic doctor } \\
\qquad(n=175)\end{array}$} & \multicolumn{2}{|c|}{$\begin{array}{l}\text { Resident/MO in restructured } \\
\text { hospital }(n=251)\end{array}$} & \multicolumn{2}{|c|}{$\begin{array}{l}\text { Public sector } \\
\text { specialist }(n=230)\end{array}$} \\
\hline & Before & After & Before & After & Before & After \\
\hline Not applicable. I do not give H\&L injections in my practice. & 40 & 48 & 164 & 163 & 161 & 165 \\
\hline $\begin{array}{l}\text { Not applicable. I give H\&L injections, but I do not } \\
\text { determine the price of the injection. }\end{array}$ & 110 & 107 & 75 & 76 & 53 & 54 \\
\hline \multicolumn{7}{|l|}{ Charge (SGD) } \\
\hline$\leq 100$ & 25 & 17 & 7 & 1 & 15 & 6 \\
\hline$>100$ to 200 & 0 & 0 & 3 & 0 & 1 & 2 \\
\hline$>200$ to 500 & 0 & 1 & 0 & 1 & 0 & 0 \\
\hline$>500$ to 1,000 & 0 & 0 & 1 & 1 & 0 & 0 \\
\hline$>1,000$ to 2,000 & 0 & 0 & 0 & 3 & 0 & 0 \\
\hline$>2,000$ to 3,000 & 0 & 0 & 1 & 1 & 0 & 0 \\
\hline$>3,000$ & 0 & 2 & 0 & 5 & 0 & 3 \\
\hline
\end{tabular}

DT: disciplinary tribunal; FP: family physician; GP: general practitioner; H\&L: hydrocortisone and lignocaine; MO: medical officer

only a total of seven doctors charged > SGD 3,000 for an H\&L injection, but this number increased more than five-fold to 37 after the decision, even though ten of these doctors were from the public sector and traditionally have been unable to determine the charges for their services. The increase in the number of doctors who charged > SGD 1,000 was even more striking, from eight to 65 , representing an eight-fold increase.

\section{DISCUSSION}

The results of this survey showed that there was a $14.6 \%$ reduction in doctors who were willing to provide $\mathrm{H} \& \mathrm{~L}$ injections. This can be considered to be an increase in the practice of avoidance defensive medicine with regard to this particular procedure. There was also an increase in price of the procedure for the patient: of those doctors who were willing to provide the service, the median price band increased from $\leq$ SGD 100 before the decision to > SGD 100 to SGD 200 after the decision. There was also a steep eight-fold increase in the number of doctors who charged $>$ SGD 1,000 for the procedure, from eight to 65 .

In the LLA case, the ethical issue underlying the complaint against the defendant doctor is that of informed consent, or the lack thereof. Informed consent can be considered to be a key pillar of the fundamental ethical principle of patient autonomy. Under the Beauchamp and Childress model of biomedical ethics, the four fundamental principles are non-maleficence, beneficence, social justice and patient autonomy. ${ }^{(13)}$

On the subject of patient autonomy and informed consent, the latest 2016 SMC Ethical Code and Ethical Guidelines states, "Patient autonomy is a fundamental principle in medical ethics and must be respected. Patients are entitled to have accurate and sufficient information to be able to make their own decisions about their medical management" ${ }^{(14)}$ In this case, the patient had complained to SMC because she felt that Dr LLA had not explained the risks and possible complications of an H\&L injection.

Sentencing is, invariably, often linked to punishment. The objectives of punishment have been described in various ways, including traditional theories of punishment, namely retribution, deterrence and rehabilitation. Contemporary alternative theories of punishment include restorative justice, expressivism, hybrid theories and unified theories. This paper will not deal with these theories but shall focus on the concept of deterrence in sentencing. This is because in the Singapore context, the C3J has 
on several occasions stated that main considerations of sentencing in disciplinary proceedings are: (a) public interest, (b) upholding public trust in the medical profession and (c) achieving effective deterrence. ${ }^{(15-17)}$ It is worthwhile to reproduce parts of the C3J Judgement in Wong Meng Hang vs. SMC: "general deterrence, in particular, is a matter of considerable importance because it is intended to create awareness in the public and more particularly among potential offenders'. This is a central and operative sentencing objective in most, if not all, disciplinary cases". It is important to note that medical indemnity insurance providers in Singapore do not cover statutory fines such as those imposed by SMC upon errant doctors. As such, the SGD 100,000 fine imposed by SMC had to be borne out of pocket by Dr LLA.

Deterrence can be subcategorised into specific deterrence and general deterrence. ${ }^{(18)}$ Specific deterrence is targeted at the offending doctor, so that he is deterred from repeating his mistakes again and the public is accordingly protected from the offender. General deterrence is the deterrent effect a sentence has on a larger group, such that the group is deterred from making the same errors as the member of the group who was sanctioned, so as to uphold the good standing of the group in society. The general deterrence sentencing objective, in this case, would be to deter registered doctors from repeating the mistake that Dr LLA had made.

In the judgement for Wong Meng Hang vs. SMC, C3J also said, "Disciplinary proceedings enable the profession to enforce its standards and to underscore to its members the value and ethos which undergird its work. In such proceedings, broader public interest considerations are paramount and will commonly be at the forefront when determining the appropriate sentence that should be imposed in each case. Vital public interest considerations include the need to uphold the standing and reputation of the profession, as well as to prevent an erosion of public confidence in the trustworthiness and competence of its members. This is undoubtedly true for medical practitioners, in whom the public and, in particular, patients repose utmost trust and reliance in matters relating to personal health, including matters of life and death" ${ }^{\prime 19)}$

Ideally, general deterrence should discourage doctors from similar mistakes that led the doctor to be found guilty of professional misconduct and uphold the standing of the medical profession in society. This is the 'positive' outcome of general deterrence. However, general deterrence outcomes may at times be contrary to the intent of the sentencing body, resulting in something very different from what was intended. This could be deemed as the negative outcome of general deterrence. Hence, the authors would like to classify general deterrence into positive and negative general deterrence. In this paper, we have demonstrated that a substantial number of doctors who previously offered H\&L injections have either ceased the practice or raised their charges. Such behavioural and practice changes can be categorised as negative general deterrence effects, as we can reasonably assume that the persons who sat in judgement of this case did not wish to see: (a) doctors charging more for an H\&L injection; or (b) doctors declining to offer the treatment when it is indicated.

\section{Box 2. Categories of defensive medicine:}

\section{Assurance behaviou}

1. Order more tests than medically indicated.

2. Prescribe more medications than medically indicated.

3. Refer patients to other specialists in unnecessary circumstances.

4. Suggest invasive procedures (e.g. biopsies) to confirm diagnoses.

\section{Avoidance behaviour}

1. Avoid certain procedures or interventions.

2. Avoid caring for high-risk patients.

Defensive medicine occurs when the doctor-patient relationship is supplanted by a doctor-potential plaintiff relationship. The doctor's decisions are no longer primarily driven by his desire to do good (benevolence) but by his perceived need to avoid being sued by a potential plaintiff. A definition of defensive medicine was given by the United States Congress' Office of Technology Assessment in its 1994 report titled 'Defensive Medicine and Medical Malpractice': "Defensive medicine occurs when doctors order tests, procedures, or visits, or avoid high risk patients or procedures, primarily (but not necessarily solely) to reduce their exposure to malpractice liability." The negative effects of defensive medicine are well documented and discussed. Broadly speaking, defensive medicine may be classified into assurance behaviour and avoidance behaviour. Major categories of assurance and avoidance behaviour by doctors practising defensive medicine are shown in Box 2.

The case at hand mainly involves avoidance defensive medicine, as previous providers of $\mathrm{H} \& \mathrm{~L}$ injections either do not offer them anymore or have attempted to price in the perceived risk of financial penalty by increasing their price for the service. The GPs/FPs who no longer offer the H\&L injection treatment may also refer these patients to specialists as part of assurance behaviour, although the survey did not evaluate this.

Defensive medicine is particularly prevalent in high-risk specialties. In a study conducted in Hiroshima, Japan, in 2006 involving gastroenterologists, $98 \%$ of respondents claimed to practise some defensive medicine: $96 \%$ of them practised some form of avoidance defensive medicine, while $91 \%$ practised assurance defensive medicine. ${ }^{(20)}$ In another study involving 824 physicians from six high-risk specialties in the state of Pennsylvania, United States, 93\% reported practising defensive medicine. ${ }^{(21)}$

There were some limitations to this study. The survey was introduced to members of both professional bodies via email. While all members of both bodies are doctors, there was no assurance that the respondents were the members themselves, as there was no verification process. Respondents could have been persons who had access to the email invitation such as staff and family members. Additionally, there was a reminder that doctors who are members of both organisations should only respond once. However, if doctors wanted to respond more than once through different Internet networks, they could do so, which would have resulted in double counting. These measures sought to ensure that respondents were doctors and that they would only respond once per respondent, but they were not foolproof and the results should be regarded accordingly. 
The post-decision survey question (i.e. Question 3) can be construed to be asking about intent rather than actual practice. As discussed above, a number of public sector doctors who signalled that they would charge more for an H\&L injection may have been answering the question from a position of intent rather than actual practice, because public sector doctors generally do not determine their charges. However, public sector doctors can refuse to give an $\mathrm{H} \& \mathrm{~L}$ injection if they choose to. As such, due to the aforesaid reasons, a small proportion of the results may be unreliable. However, this does not detract from the overall findings of this survey, which show a change in the behaviour of doctors regarding the provision of $\mathrm{H} \& \mathrm{~L}$ injections before and after the GD for the LLA case was delivered by the SMC DT.

The authors of this paper believe that this change in behaviour is largely attributable to a shift by a group of respondents towards practising defensive medicine. However, another explanation for this shift could be that doctors are now more careful and selective in choosing patients for whom $H \& L$ injections are truly indicated. However, this should be a small group given the natural history of conditions that will benefit from such injections: musculoskeletal conditions such as tendinitis often present with pain, inflammation, swelling and limited movement, which are quickly resolved by an $\mathrm{H} \& \mathrm{~L}$ injection. It would be rather difficult for a doctor to offer an H\&L injection to patients who do not already suffer from significant, debilitating symptoms. They are more likely to be seeking alleviation for conditions that would benefit from $\mathrm{H} \& \mathrm{~L}$ injections. In other words, overservicing is probably not common given the nature of these conditions and the treatment being provided.

We did not have the opportunity to explore in this paper the other reasons behind this shift in behaviour beyond the decision of the DT, which was a fine of SGD 100,000 for the defendant doctor. Other possible contributory factors were a perceived change in the policy position of SMC regarding what constitutes adequate punishment, as seen in the request for a suspension of five months by the counsel for SMC, or doctors' generally poor understanding of the SMC Ethical Code and Ethical Guidelines, which spells out prevailing ethical standards expected of doctors.

This paper was deliberately structured as a descriptive study; inferential statistics involving a null hypothesis and analysis of statistical significance were intentionally avoided. This is because in economics and the setting of prices, it is difficult to establish what is considered statistically significant. For example, a $2 \%$ inflation rate is no less statistically significant than a $4 \%$ inflation rate. The same consideration applies to prices, especially when we have to decide the reference point from which changes in prices are taken: a SGD 5 change in price may be insignificant to a doctor or a rich patient, but quite significant to a patient of especially limited financial means.

In conclusion, there have been several studies on the prevalence of defensive medicine. ${ }^{(9,21,22)}$ However, to our knowledge, this study is the first of its kind to document the impact of a disciplinary body's decision on the practice behaviour of a cohort of doctors in two aspects, namely avoidance behaviour and change in price for a service/procedure. The reduction in the number of providers willing to offer $\mathrm{H} \& \mathrm{~L}$ injections, together with the increased charges for this procedure, would likely lead to a rise in healthcare costs that would have to be borne by healthcare providers, patients or third-party payers. Our study highlights the possible consequences of deterrence sentencing in the specific area of general deterrence. Consequences can be positive when the deterrent effect is as intended. However, when the deterrent effect is unintended, its negative consequences may subsequently lead to increased social and financial costs that have to be borne by patients and the society.

\section{REFERENCES}

1. Singapore Medical Council. Annual Report 2017 [online]. Available at: https://www.healthprofessionals.gov.sg/docs/librariesprovider2/publicationsnewsroom/smc-annual-reports/annual-report-2017.pdf. Accessed July 24, 2019.

2. Singapore Medical Council Disciplinary Tribunal. Dr Lim Lian Arn [2018] SMCDT 9; Grounds of Decision, para 26.

3. Singapore Medical Council Disciplinary Tribunal. Dr Lim Lian Arn [2018] SMCDT 9; Grounds of Decision, para 25.

4. Singapore Medical Council Disciplinary Tribunal. Dr Lim Lian Arn [2018] SMCDT 9; Grounds of Decision, para 48.

5. Singapore Medical Council Disciplinary Tribunal. Dr Lim Lian Arn [2018] SMCDT 9; Grounds of Decision, para 49.

6. Singapore Medical Council Disciplinary Tribunal. Dr Lim Lian Arn [2018] SMCDT 9; Grounds of Decision, para 51.

7. Singapore Medical Council Disciplinary Tribunal. Dr Lim Lian Arn [2018] SMCDT 9; Grounds of Decision, para 55.

8. Singapore Medical Council Disciplinary Tribunal. Dr Lim Lian Arn [2018] SMCDT 9; Grounds of Decision, para 57.

9. Change.org. What is the Ministry of Health's stand on informed consent for minor procedures? [online]. Available at: https://www.change.org/p/whatis-the-ministry-of-health-s-stand-on-informed-consent-for-minor-procedures. Accessed April 9, 2019.

10. Singapore Medical Council. Doctors not expected to inform patients of all possible complications [online]. Available at: https://www.healthprofessionals. gov.sg/docs/librariesprovider2/default-documentlibrary/clarification-statement(30-jan-2019).pdf. Accessed April 9, 2019.

11. Ministry of Health Singapore. MOH statement on SMC DT inquiry for Dr Lim Lian Arn [online]. Available at: https://www.moh.gov.sg/news-highlights/details/ moh-statementon-smc-dt-inquiry-for-dr-lim-lian-arn. Accessed April 9, 2019.

12. Singapore Medical Association. SMA 59th Annual Report 2018/2019 [online]; p. 14. Available at: https://www.sma.org.sg/Uploadedlmg/files/01SMA59thAnnualReport.pdf. Accessed April 9, 2019.

13. Beauchamp TL, Childress JF. Principles of Biomedical Ethics. 7th ed. Oxford: Oxford University Press, 2012.

14. Singapore Medical Council. SMC Ethical Code and Ethical Guidelines [online]. 2016 Edition; p. 36. Available at: https://www.healthprofessionals.gov.sg/docs/ librariesprovider2/guidelines/2016-smcethical-code-and-ethical-guidelines--(13sep16).pdf. Accessed April 9, 2019.

15. Low Cze Hong v. Singapore Medical Council [2008] SLR(R) 61(8), para 88.

16. Singapore Medical Council v. Kwan Kah Yee [2015] SGC 3], para 55.

17. Wong Meng Hang v. Singapore Medical Council [2018] SGHC 253, para 23-25.

18. Ang Peng Tiam v. Singapore Medical Council [2017] SGHC 143, para 89.

19. Wong Meng Hang v. Singapore Medical Council and other matters [2018] SGHC 253, para 23.

20. Hiyama T, Yoshihara M, Tanaka S, et al. Defensive medicine practices among gastroenterologists in Japan. World J Gastroenterol 2006; 12:7671-5.

21. Studdert DM, Mello MM, Sage WM, et al. Defensive medicine among highrisk specialist physicians in a volatile malpractice environment. JAMA 2005; 293:2609-17.

22. Mello MM, Chandra A, Gawande AA, Studdert DM. National costs of the medical liability system. Health Aff (Millwood) 2010; 29:1569-77. 